FIGUEIRÔA, Silvia F. de M. 'Batedores da ciência' em território paulista: expedições de exploração e a ocupação do 'sertão' de São Paulo na transição para o século XX. História, Ciências, Saúde - Manguinhos, Rio de Janeiro, v.15, n.3, p.763-777, jul.-set. 2008.

\title{
'Batedores da ciência' em território paulista: expedições de exploração e a ocupação do 'sertão' de São Paulo na transição para o século XX
}

\section{Trailblazers of science in the São Paulo territory: exploratory expeditions and the settlement of the São Paulo 'sertão' at the turn of the twentieth century}

Silvia F. de M. Figueirôa

Departamento de Geociências Aplicadas ao Ensino Instituto de Geociências/Universidade Estadual de Campinas Caixa Postal 6152

13081-970 Campinas - SP Brasil

figueiroa@ige.unicamp.br

Recebido para publicação em julio 2007

Aprovado para publicação em mayo 2008.

\section{Resumo}

Este artigo apresenta e discute a participação da Comissão Geográfica e Geológica de São Paulo, fundada em 1886, na cartografia e nos levantamentos de recursos naturais do território paulista a fim de viabilizar sua exploração econômica e ocupação agrícola, industrial e urbana. Coube à ciência e à técnica uma participação decisiva nesse processo, em que se confirma o papel mediador entre ciência e sociedade das instituições de pesquisa, particularmente a aplicada. A ação da Comissão viabilizou a montagem de uma rede de comunicação viária, seja fluvial ou ferroviária, tanto simultaneamente aos levantamentos quanto a posteriori, em decorrência da abertura de frentes territoriais de ocupação geográfica.

Palavras-chave: sertão; Comissão Geográfica e Geológica; São Paulo; Brasil.

\section{Abstract}

Founded in 1886, the São Paulo Geographic and Geological Commission took part in cartographic studies and surveys of the region's natural resources that were essential to the economic exploitation of these resources and to agricultural, industrial, and urban settlement. Science and technology played a decisive role in this process, where research institutions especially those in applied research - acted as intermediaries between science and society. The Commission's work made it possible to set up a communication network, including river and rail, both during and after the surveys, as new frontiers were being opened and settled.

Keywords: sertão; Geographic and Geological Commission; São Paulo; Brazil. 
$\mathrm{A}$ o findarem os trabalhos de campo das expedições empreendidas pela Comissão Geográfica e Geológica de São Paulo (CGG) para levantamentos gerais do chamado 'sertão' - como era então denominada vasta área a oeste do estado, o secretário de Agricultura de São Paulo da época, Carlos José de Arruda Botelho, filho do visconde do Pinhal e destacado representante das elites cafeicultoras paulistas, assim se manifestava ao chefe da Comissão, em 13 de dezembro de 1906: "Por ter sido sob a vossa direção que o governo [de São Paulo] se habilitou para anunciar às sociedades geográficas do mundo que mais uma parcela do globo terrestre vai ser entregue ao esforço civilizador dos povos, porquanto por ali acabam de transitar os batedores da ciência, representados pela Repartição que dirigis, apresento-vos as minhas felicitações" (Botelho, 13 dez; 1906).

Nesse curto trecho de discurso oficial afloram alguns elementos importantes para a discussão que é objeto deste artigo. Primeiro, o tom evidentemente ufanista e exagerado do discurso. Segundo, o elogio do Progresso material, que obrigatoriamente acompanha aquilo que se chamava de Civilização - ambos os conceitos, obrigatoriamente, grafados com maiúsculas e no singular, posto que eram entendidos como únicos e superiores ao status quo vigente. Como bem esclarece Moraes (2003), 'sertão' não define, a priori, uma região específica, com meio físico e ecologia própria, singular. Ao contrário, é sempre um 'outro' geográfico, alteridade que nos define por ser aquilo que não somos - ou não queremos ser. Assim, o 'sertão' paulista era entendido como o lugar, imaginário e real, a ser transformado pela modernidade do novo século XX.

Em terceiro lugar, destaca-se no discurso o papel fundamental da ciência nesse processo de apropriação do território, com seus recursos naturais e humanos. E aqui é imprescindível incorporar à discussão, logo de início, o conceito de 'fundos territoriais', a fim de permitir uma compreensão, melhor situada historicamente, dos esforços de 'conquista' desses espaços da hinterlândia de São Paulo, então entendidos como asilados do que se considerava ser o 'destino natural' das regiões - ou seja, desenvolvimento econômico. Os fundos territoriais consistem em áreas não devassadas, autênticos estoques de terras e recursos naturais para apropriação futura, como os sertões e as áreas de fronteiras, por exemplo (Moraes, 2004). A existência e disponibilidade de recursos naturais sempre constituíram vetores positivos da expansão colonial desde o século XV, pelo menos (Moraes, 2004), o que só foi reforçado ao longo do tempo. Em São Paulo, em pleno século XX, ainda restavam vastos espaços por explorar - mas antes era preciso conhecê-los em detalhe, esquadrinhá-los minuciosa e cientificamente, tarefa que coube à CGG.

\section{Avançar e ocupar o"sertão desconhecido habitado por indígenas selvagens"}

A disponibilidade de solos adequados à agricultura, particularmente à cafeicultura, era quase interdependente da existência de vias de transporte, pois de nada valia encontrar solos férteis se a eles não se tinha acesso. Desde 1855, pelo menos, encontramos manifestações oficiais a respeito desse tema, como quando o presidente da província de São Paulo, José Antonio Saraiva, assim se manifestou à Assembléia: "[há] necessidade de dados geográficos com os quais se possa entrar no conhecimento exato da direção atual dos caminhos, e de seus defeitos, e bem assim da melhor direção a dar às nossas linhas de comunicação ..." (citado em Derby, 1889, p.8). 
Novamente em 1866, o presidente de turno, conselheiro João da Silva Carrão, voltava à carga:

a existência de vias de comunicação que dêem fácil e pronta circulação aos produtos ... é a primeira necessidade da indústria moderna; é hoje dogma da civilização. Infelizmente a Província de São Paulo acha-se em estado, relativamente a vias de comunicação no interior, que só tem o deplorável préstimo de fazer admirar a perseverança, a energia indomável de sua população. ... Merecem desde já atrair a atenção desta Assembléia os rios Pardo, Mogi-Guaçu, Tietê e mesmo o Paranapanema. Os primeiros servirão de auxiliares poderosos à estrada de ferro de Santos a Jundiaí, cujo prolongamento para o interior é uma necessidade indeclinável. Os terrenos para os quais dirige-se a mencionada estrada são de uma fertilidade abismadora, e só esperam a construção de meios fáceis de comunicação para receberem braços e capitais que, aplicados por indústria inteligente, ofereçam a extraordinária produção que a natureza ali prodigamente promete (Carrão, 1866, p.42).

Poderíamos citar outros relatórios oficiais de presidentes paulistas que trataram enfaticamente dessa mesma questão - como os de José Tavares Bastos (1867) ou de Francisco Xavier Pinto Lima (1872) -, mas, além de certamente cansar os leitores, apenas reforçaria a constatação de que o problema era objeto permanente de atenção governamental. Preferimos aproveitar a própria fala do presidente Carrão para destacar dois pontos fundamentais da demanda ligada às vias de comunicação, que ilustram as interconexões mencionadas. $\mathrm{O}$ primeiro refere-se à importância conferida aos cursos d'água, revelando que, ao se pensar em vias de comunicação na época, já se pensava num sistema viário capaz de atender e integrar as regiões mais distantes da província. Não se tratava, apenas, de implantação de ferrovias essenciais, sem qualquer dúvida -, mas pretendia-se, ao menos no nível dos projetos, a integração destas com os rios e outros caminhos existentes. Pensada como extensão da rede ferroviária, a navegação fluvial merece ser destacada como parte significativa desse plano de transportes, cujo objetivo básico era viabilizar a incorporação, ao processo produtivo, de regiões inacessíveis às estradas de ferro nas circunstâncias da época, como já foi dito acima.

$\mathrm{O}$ segundo ponto toca o eixo das questões relativas às terras. Em seu avanço rumo às terras férteis do Oeste de São Paulo, a lavoura enfrentava o sério obstáculo do escoamento dos produtos. De que adiantaria uma alta produção, se o custo envolvido com seu transporte até os centros distribuidores igualaria, ou mesmo superaria, o lucro obtido? Esse problema, por sinal, marcou todo o mundo ocidental moderno, à época: as tecnologias disponíveis, principalmente a da estrada de ferro e a do vapor, possibilitaram inserir regiões outrora inacessíveis nos domínios dos mercados produtores-consumidores mundiais (Hobsbawm, 1979, p.194). Contribuía para a pressão sobre a região do Oeste de São Paulo a crença largamente fundamentada de que suas terras eram 'ubérrimas':

Um relatório publicado na Corte pelo sr. dr. Pimenta Bueno, chefe da turma de engenheiros empregada nas explorações a que aludimos [levantamentos para prolongamento de estradas de ferro], apregoa com dados amplos e seguros as riquezas espalhadas na direção tomada para suas experiências [Oeste]. É tempo de olhar-se para elas com a atenção e o cuidado necessário. Temos por aquelas bandas um manancial inesgotável e de imenso alcance para a prosperidade social (Santos, 7 jun. 1874).

A ocupação e integração do sertão de São Paulo aos fluxos da economia cafeeira e do complexo agroexportador já estava, assim, na base da criação da CGG em 1886. Conforme 
se expressava o presidente da província, conselheiro João Alfredo Corrêa de Oliveira, no relatório encaminhado ao Legislativo em 15 de fevereiro de 1886 e que serviria de justificativa do projeto:

Entre os embaraços com que luta a administração da Província para formar um plano geral que atenda às necessidades do seu desenvolvimento ... avulta a ausência de informações exatas e minuciosas sobre a geografia, relevo do solo, vias de comunicação, estrutura geológica, riqueza mineral e caráter das diversas qualidades de terras. É a meu ver uma das mais urgentes necessidades da Província [de São Paulo] o estudo de seu território; e é fora de dúvida que os dispêndios que esta notável empresa houver de determinar serão compensados não só pela expansão que à riqueza pública trará o aproveitamento de recursos naturais cujo valor ficará conhecido, como também pelos preciosos elementos que ela ministrará à solução do problema da colonização (Oliveira, jan.-mar. 1966).

O projeto de criação da CGG, por sua vez, previa com clareza em seu escopo:

a organização de cartas, na escala de um centímetro por quilômetro, que serão ao mesmo tempo geográficas, topográficas, itinerárias, geológicas e agrícolas, e em que se representem exatamente todos os centros de população e os estabelecimentos industriais e agrícolas de certa importância; ... as estradas de ferro e de rodagem; os cursos d'água; as minas, etc.; ... a distribuição dos terrenos geológicos e das terras de cultura e criação, bem como das improdutivas (Oliveira, jan.-mar. 1966).

Não é o caso de repetir, neste texto, a história da CGG, já largamente pesquisada e discutida em diversos textos (Figueirôa, 1987, 1997, 2007; Newerla, 2000), tampouco a história da economia cafeeira, também sobejamente conhecida. Para o objetivo do presente artigo, que é o de investigar algumas relações que se estabeleceram entre expedições científicas e a construção de redes de comunicação e transporte, são ressaltados, justamente, o conteúdo de documentos e trechos dos discursos neles presentes que enfatizaram os problemas de acesso a extensas porções das terras paulistas. Tais questões estavam direta e intimamente ligadas às demandas postas pela expansão da cafeicultura, que se articulavam e complementavam em torno de três eixos: disponibilidade de solos para cultivo (pois o esquema de produção do café era a plantation); construção e melhoria da infra-estrutura de transporte e escoamento da produção (visando à exportação); e abastecimento de mão-deobra (sobretudo ao final do Império, com a crise da escravidão).

Cabe, no entanto, para melhor situar os leitores, retomar em linhas bastante gerais a história da Comissão Geográfica e Geológica de São Paulo, criada pela lei provincial $n^{\circ} 9$ em 27 de março de 1886, às vésperas da República. A instituição sintetizou a opção pela via tecnocientífica como alternativa para solução de parte significativa dos citados problemas que afligiam a expansão da economia cafeeira, refletindo a visão de uma sociedade já transformada pelo próprio processo de modernização, com o qual a CGG deveria interagir nos anos subseqüentes (Figueirôa, 1987). O projeto de lei foi apresentado à Assembléia Provincial por um dos mais proeminentes cafeicultores de São Paulo, o visconde do Pinhal, e assinado por seus outros colegas de bancada, todos do Partido Liberal. Depois de uma tramitação extremamente rápida, de apenas cinco dias, foi aprovado por unanimidade. Tais rapidez e consenso explicam-se, seguramente, pelas emblemáticas palavras do cafeicultor conselheiro Antônio da Silva Prado, influente protagonista da cena nacional: "Uma das 
razões, se não a razão principal da prosperidade da minha província [São Paulo], é que o paulista não politica em se tratando de melhoramentos materiais. Há ali estradas de ferro, empresas de navegação e outras organizadas por iniciativa de conservadores, liberais e republicanos, os quais sabem esquecer dissentimentos quando o seu concurso é exigido a bem da província" (citado em Casalecchi, 1987, p.20) - entenda-se, em seu próprio benefício...

Logo a seguir, em 7 de abril, foram baixadas instruções de trabalho que visavam orientar os levantamentos e as expedições, além de reiterarem o "valor econômico" e a necessidade de "aplicação prática" dos estudos (Resolução..., jan.-mar. 1966). O chefe e proponente do plano científico institucional foi o naturalista e geólogo Orville Adelbert Derby (18511915), norte-americano graduado na Universidade de Cornell (EUA) que trabalhava no Brasil desde 1875, primeiro como membro da Comissão Geológica do Império (1875-1877) e, a seguir, na Seção de Geologia do Museu Nacional. Por sua concepção de ciência e pelas características de sua formação, Derby imprimiu à CGG, no período em que esteve na direção da instituição (1886-1905), um enfoque que classificamos de 'naturalista', em virtude da abrangência disciplinar (geografia, geologia, geodésia, botânica, meteorologia, zoologia, etnografia) aliada ao caráter de descrição minuciosa (Figueirôa, 1987).

A primeira expedição de exploração tinha por objetivo fazer o levantamento pormenorizado dos rios Itapetininga, Paranapanema e seus afluentes, sobretudo quanto às condições de navegabilidade. Partiu quase que imediatamente após a publicação das instruções e atingiu o Paranapanema em menos de uma semana. O produto do trabalho foi o Relatório de exploração dos rios Itapetininga e Paranapanema, saído dos prelos em 1889. Este relatório é um estudo bastante detalhado e preciso do curso dos rios, exibindo perfis sistemáticos com as desejadas informações sobre navegabilidade, complementadas por sugestões de obras nos locais avaliados como problemáticos para essa finalidade. O restante dos dados coletados, inclusive um vocabulário da língua Caiuá, foi publicado em 1890 num Boletim da CGG (o de número 4) - Considerações geographicas e econômicas sobre o valle do Paranapanema.

Nos 15 anos seguintes a CGG não realizou qualquer expedição, tendo privilegiado os serviços de meteorologia e de botânica aplicada (também essenciais para a agricultura) e a cartografia sistemática das regiões há tempos ocupadas em São Paulo. Essa opção de trabalho, sem dúvida, contrariou diversos interesses, especialmente o dos grandes plantadores de café, que viram frustrados seus planos de avanço rumo ao Oeste. Sem possibilidade de negociar novas orientações com Orville Derby, o governo substituiu-o pelo engenheiro João Pedro Cardoso (1871-1950?), o qual, com perfil profissional e científico bastante diferente, conferiu uma marca mais pragmática, de aplicação dos saberes, a essa nova fase da instituição e permitiu que os 'batedores da ciência' finalmente penetrassem na região.

Cardoso foi o segundo e último chefe da CGG enquanto a instituição existiu com tal denominação e, grosso modo, nos mesmos moldes de trabalho, até 1931. Ao longo de 45 anos, o CGG foi matriz de instituições que se mantêm no sistema científico e tecnológico de São Paulo até hoje: Instituto Geológico, Instituto Geográfico e Cartográfico, Instituto de Botânica, Instituto Florestal, Instituto Astronômico e Geofísico, Museu Paulista e Museu de Zoologia. Na década de 1920, foi pioneira na exploração do subsolo paulista, por meio 
do Serviço de Petróleo e do Serviço da Apatita (que explorava jazidas desse mineral de fosfato para a produção de fertilizantes).

\section{A 'conquista do Oeste'}

Como se vê, avançar rumo ao Oeste e ocupá-lo, tornando-o 'produtivo', substituindo o 'sertão' pela 'civilização', era meta estabelecida já de longa data, que embasou e justificou a própria fundação da CGG. No entanto, essa exploração não ocorreu de imediato, como dissemos. Compreende-se, assim, o regozijo do secretário da Agricultura quase vinte anos depois, pois até então os mapas de São Paulo representavam esta vasta área como um 'vazio geográfico', a respeito do qual não se dispunha de informações seguras. Empregavase correntemente a expressão 'terrenos desconhecidos', muitas vezes seguida de 'habitados por indígenas selvagens', carregadas de uma ideologia preconceituosa e sinalizadoras da defesa de submissão ou extermínio indígena. A questão, aliás, foi objeto de um debate bastante inflamado na época, sobre o qual existe uma expressiva literatura. Entretanto entendemos que seu aprofundamento, aqui, desvia o texto de seu foco principal.

Sem dúvida, uma clara interface entre expedições de exploração e sistemas de transporte e comunicação denota-se com a intenção, por parte daquelas, de recorrer a estes, tanto para atingir as regiões almejadas quanto para trocar mensagens com a sede. No caso das expedições de exploração do extremo Oeste de São Paulo, a comunicação se fazia de duas maneiras: por meio dos telégrafos elétricos, com mensagens enviadas e recebidas pelas turmas de exploração a partir de estações localizadas nas ferrovias e nos principais centros de população (cidades ou vilas mais importantes); e por meio de cartas redigidas pelos chefes das expedições e endereçadas ao chefe da CGG, que permanecia na capital quase todo o tempo. Essa significativa documentação encontra-se preservada e armazenada no Arquivo Histórico do Instituto Geológico de São Paulo, compondo dossiês de cada expedição. Ela indica que os telegramas serviam, como seria de esperar, para pedidos breves e urgentes, tais como dinheiro para compra de mantimentos, aluguel de animais, pagamento de hospedagem nos núcleos populacionais e cidades pioneiras, remuneração dos trabalhadores locais, contratados para a empreitada (chamados de 'camaradas') etc. Já as cartas constituíam autênticos relatórios de atividades, com todo tipo de informação do dia-a-dia das expedições, incluindo dados tecnocientíficos.

Um outro uso freqüente do sistema viário e de comunicação dessa época é muitas vezes esquecido. Os cortes das estradas de ferro, das linhas telegráficas e das barrancas ou corredeiras dos rios constituíam pontos privilegiados de observação, especialmente para os saberes ligados à terra, posto que facilitavam o exame e mesmo a coleta dos materiais in situ, garantindo suas localizações geográficas, crono e paleoestratigráficas, além de oferecerem material 'fresco' para análise - isto é, material ainda não completamente alterado pelo intenso intemperismo das regiões tropicais e subtropicais. Tal fato tem bastante relevância, pois exemplares de fósseis e rochas bem preservados permitem exame mais acurado de características morfológicas, texturais e composicionais e, conseqüentemente, identificação mais precisa.

No entanto, neste artigo pretendemos comentar mais do que isso. As expedições empreendidas pela CGG, com mais vigor a partir de 1905, visavam subsidiar científica e 
tecnicamente a expansão da malha da infra-estrutura fundamental à economia cafeeira de São Paulo. Como bem mostrou Sérgio Milliet há quase setenta anos, em seu estudo Roteiro do café, há muito considerado um clássico, com exceção das zonas Norte (Vale do Paraíba), Central (Capital, São Roque, Campinas, Bragança e arredores) e Mogiana-Paulista, onde o café chegara antes de 1860, nas chamadas Zonas Novas - ou seja, o 'Oeste' - seu 'desbravamento' não antecedeu, mas sim acompanhou as estradas de ferro. O café aí aportou ao final do século XIX e reinou absoluto até 1935, decuplicando a produção por duas vezes (de 1886 a 1920 e de 1920 a 1935) (Milliet, 1982, p.55). Acreditamos que o trabalho da CGG esteve inseparavelmente ligado a essa expansão.

A exploração do 'extremo sertão' de São Paulo foi objeto específico de decreto governamental (1.278) em 23 de março de 1905, que também instruía o modo como os trabalhos deveriam se desenvolver. Foram organizadas quatro expedições que, percorrendo os rios Tietê, Feio, Peixe e Paraná, realizariam o mapeamento da região 'desconhecida', cujos limites eram: ao norte, a margem esquerda do Tietê até a confluência com o rio Paraná; a oeste, desta confluência até a barra do rio Santo Anastácio; das vertentes da margem direita do Santo Anastácio até o ribeirão Laranja Doce e, subindo a Serra dos Agudos, até o rio Feio, no limite sul; e, a leste, por uma linha do rio Paranapanema ao salto do Avanhandava, cortando o rio Feio e a Serra dos Agudos. Os objetivos específicos diferem um pouco: nos dois primeiros rios, Tietê e Paraná, o interesse mais forte foi pelo levantamento detalhado das cachoeiras; nos outros rios, Feio/Aguapeí e Peixe, o foco foi o reconhecimento do 'sertão' e a abertura de vias de acesso (Newerla, 2000, p.51).

As partidas dos grupos pelos rios, festejadas com salvas de tiros, foram quase simultâneas, o que sem dúvida aumentou as dificuldades de gerenciar o empreendimento à distância, pois a sede da instituição encontrava-se na capital, São Paulo. A expedição dos rios Feio e Aguapeí partiu em 10 de maio de 1905; a do rio Paraná, em 19 do mesmo mês; a do rio do Peixe, no dia 21; e a do rio Tietê, três dias depois ( 24 de maio). As instruções previam a contratação de estafetas para manter a comunicação com o chefe João Pedro Cardoso, que, por sua vez, agiria junto ao governo estadual.

Com uma suplementação de verbas da ordem de $40 \%$ de seu orçamento para o ano de 1905, devida ao decreto, a Comissão contratou novos técnicos e montou quatro equipes de campo, uma para cada expedição, as quais foram, em média, cinco vezes maiores do que o grupo da única exploração anteriormente realizada, aquela encarregada do levantamento dos rios Itapetininga e Paranapanema, em 1886. Muitos técnicos foram dispensados ou saíram por vontade própria já no final de 1905, quando o trabalho de campo estava praticamente concluído. Outros, porém, se fixaram e permaneceram na instituição até a década de 1930.

Os relatórios publicados dessas expedições constituem um minucioso inventário do meio e dos recursos naturais das áreas palmilhadas e demonstram obediência fiel às instruções contidas no decreto, visando a apropriação dos espaços em futuro não muito distante. Como afirma em seu relatório o coronel Cornélio Schmidt, engenheiro-chefe da expedição do rio Paraná:

o Governo do Estado não tem poupado esforços e dinheiro no afã patriótico e louvável de descortinar, povoar e civilizar o extremo sertão do Estado. ... fui incumbido de organizar esta última [Paraná] e dirigi-la de conformidade com as instruções baixadas com o decreto citado 
[1.278], às quais procurei dar cumprimento tendo sempre em vista obter a maior soma de dados que trouxesse o pleno conhecimento da região, tanto sob o ponto de vista técnico como de outros que, para o futuro aproveitamento da região, fossem de interesse ... (São Paulo, 1911, p.15).

De modo geral, os relatórios organizam-se da seguinte maneira: uma apresentação escrita pelo chefe da CGG, seguida de uma introdução de autoria do chefe de cada expedição; textos técnicos sobre diferentes conteúdos técnicos - geografia, geologia, botânica, meteorologia, coordenadas geográficas, população e núcleos populacionais da região percorrida, presença de índios etc. Os textos impressos são intercalados com páginas de fotografias e, ao final, encontram-se as cartas e mapas elaborados. Diferentes tipos de informação são destacados nos textos, conforme a função exercida pelo engenheiro (ou médico) que reúne os dados no impresso. Em que pesem as variações entre os quatro relatórios de exploração, merecem destaque alguns pontos comuns, cuja simples presença reveste-se de grande significado. São eles: a exaltação à exuberância e à riqueza do meio natural, em especial as cachoeiras e quedas d'água; a superioridade da ciência e da técnica em detrimento dos saberes indígenas e 'caboclos'; a inexorável 'marcha do progresso' e conseqüente assimilação dessas regiões à 'civilização', como se fora um desdobramento futuro 'natural'; a presença de farta documentação fotográfica, que não apenas ilustra ou confere status de prova ao que foi visto, mas produz um discurso visual próprio, que reverbera e reforça o discurso textual (Figueirôa, set.-dez. 1987); mapas, cartas e perfis dos rios percorridos, atentando-se para as condições de navegabilidade e, conseqüentemente, para a integração ao sistema de transportes, como ilustra a Figura 1. Vale a pena exemplificar cada um desses aspectos com trechos extraídos dos relatórios.

No caso da região 'desbravada' pela expedição dos rios Feio e Aguapeí, o texto adota um tom premonitório: "riquíssima de terras de primeira sorte, dotada de um clima esplêndido, está fadada a ser, dentro em pouco, mais um centro de riqueza e de prosperidade do estado de São Paulo" (São Paulo, 1910, p.10).

Já em relação ao rio Paraná, é o antigo projeto de constituição de um sistema viário adequado à economia agroexportadora que se manifesta, em tom profético:

seus afluentes ... vêm auxiliar a rede fluvial que forma a bacia do Paraná, a qual virá prestar um poderoso auxílio para o desenvolvimento dessa grande zona central logo que seja estabelecida a navegação desse rio-mar e escolhidos alguns pontos para serem atingidos pelas nossas estradas de ferro, as quais facilitarão o povoamento desta vasta região ... e que muito em breve virá concorrer para o progresso de nossa pátria (São Paulo, 1911, p.11; grifos do original).

Na expedição do rio Tietê, o foco recai nas possibilidades de aproveitamento da energia hidráulica para sua transformação em eletricidade, acompanhando a modernidade dos tempos, fato que visivelmente empolga o autor do texto:

A $157,5 \mathrm{~km}$ do rio Jacaré Grande encontra-se o Salto do Avanhandava, que é uma das maiores riquezas naturais que possui o Estado de São Paulo, e que aguarda futuro não muito remoto para vir a contribuir para a grandeza e prosperidade da indústria entre nós. A posição do salto indica que teremos aí uma grande fonte de atividade quando houver meios de transporte rápido, ou quando suas águas passarem pelos mecanismos e imprimirem força, produzirem 
energia elétrica, etc., eliminando o combustível e levando a grande distância a ação do seu valor e da sua importância como grande fator do desenvolvimento da produção, em vez de rolarem livremente sobre blocos de grez [arenito], cobrindo-os de alta espuma branca e fazendo desprender nuvens multicores a perderem-se no infinito, como que anunciando que aí será mais tarde um centro de irradiação de trabalho e progresso (São Paulo, 1930, p.ii; grifos meus).

A presença indígena, sinônimo de ausência de 'civilização', é igualmente condenada, na mesma frase que aponta a abertura de uma importante via de comunicação, a qual permitiria, a um só tempo, o acesso e a 'redenção': “o picadão do curso superior do Rio Feio constitui uma veia vital desta parte do sertão desconhecido de S. Paulo e em breve será um meio poderoso para arrancar dos índios selvagens desta zona estes seus imensos campos de caçada, entregando-os à civilização" (São Paulo, 1910, p.18).

O chamado Picadão do Rio Feio é talvez o melhor exemplo, neste artigo, do tema que se aborda neste número de História, Ciências, Saúde - Manguinhos. Na época, a cidade de Bauru era, a oeste, o limite acessível por ferrovia e outros caminhos, consistindo portanto numa 'boca de sertão'. A turma de exploração dos rios Feio e Aguapeí chegou até lá de trem, mas suas tarefas técnicas deveriam começar a partir dali. A construção do Picadão era parte essencial de seu trabalho. Aberto na mata fechada, avançava com enormes dificuldades, devidas, além da própria vegetação, ao terreno areno-argiloso (afinal, tratase da bacia sedimentar do Paraná), às chuvas e áreas alagadas (que requeriam, para sua travessia, construção de passadiços), à presença de índios (que atacaram a expedição em determinado momento, provocando a substituição de seu chefe) e à falta de víveres e dinheiro para comprá-los, assim como para pagamento dos trabalhadores locais. Enfim o Picadão atingiu a marca de $100 \mathrm{~km}$ de extensão, um feito marcado com foto, a atestar o desafio cumprido, a façanha realizada. Porém, mais do que isso, deixou aberta a veia para o ingresso do café, das fazendas, dos colonos, dos caminhos de ferro, da urbanização - do 'progresso', em suma.

Completada a tarefa de entregar à 'civilização' o sertão do extremo Oeste, haveria ainda outros sertões a desbravar em São Paulo, até então 'abandonados' à própria sorte, sem conhecerem as maravilhas civilizadas? Parece que sim, sem dúvida. No relatório do chefe da CGG ao governo do estado sobre as atividades da Comissão em 1910 - um dos anos mais produtivos, segundo João Pedro Cardoso -, este afirma claramente:

ainda nos restava a enorme Zona Norte do Estado, fronteira ao Triângulo mineiro e tendo como divisa o caudaloso Rio Grande. Impunha-se a sua exploração não só pela contribuição geográfica, como também pela série de belezas e riquezas que lá se acham no mais completo abandono, representando uma verdadeira reserva para auxiliar o progresso do Estado de São Paulo. São florestas, são terras de boa qualidade, são cachoeiras e saltos de forças colossais que aguardarão um futuro não muito remoto para virem auxiliar poderosamente o desenvolvimento crescente de São Paulo (São Paulo, jun. 1911, p.1).

Vê-se que nada poderia sobrar intocado - 'riquezas naturais' só existem se forem apropriadas, justamente reconceituadas pelo próprio processo que delas se utiliza e as transforma. 
Silvia F. de M. Figueirôa

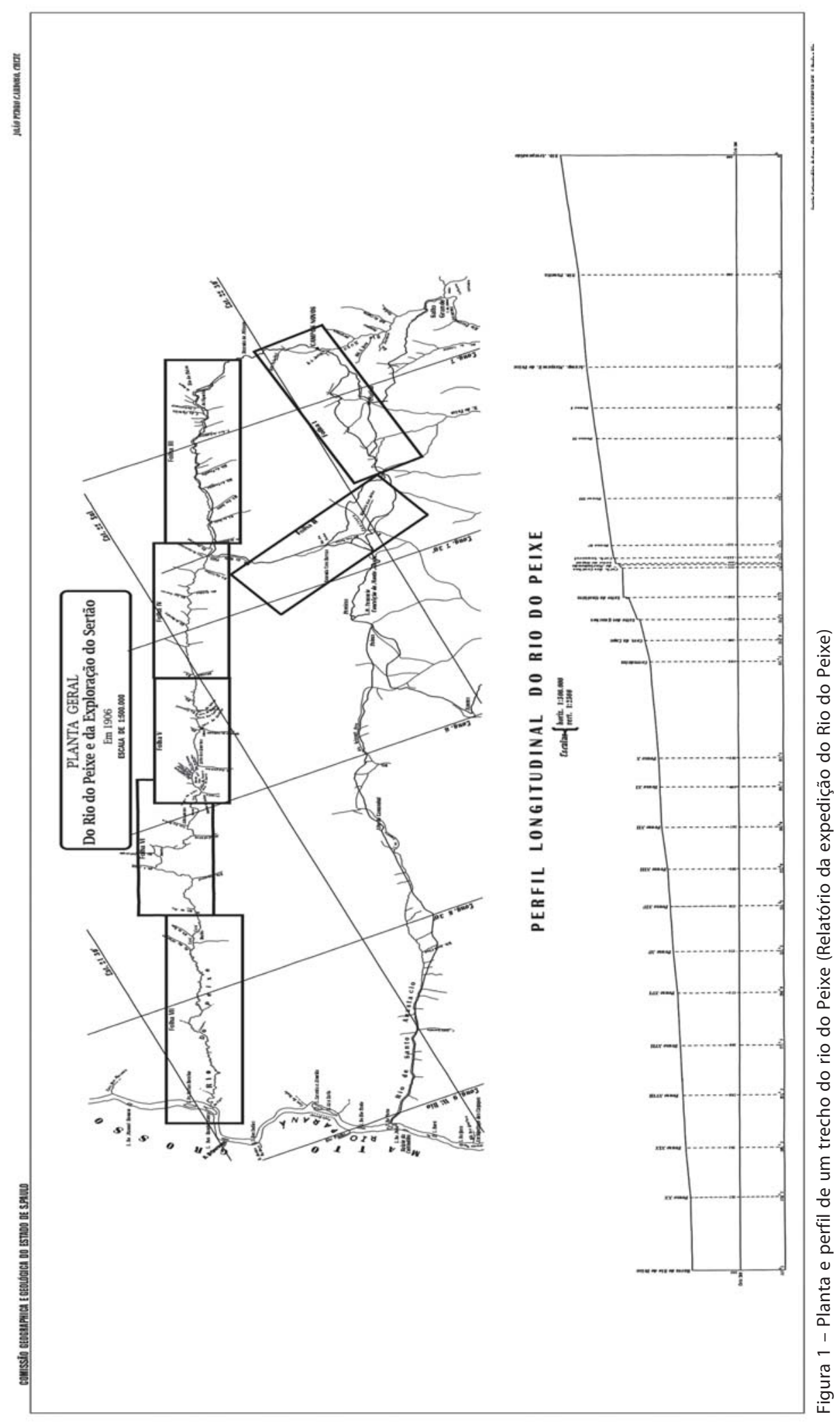




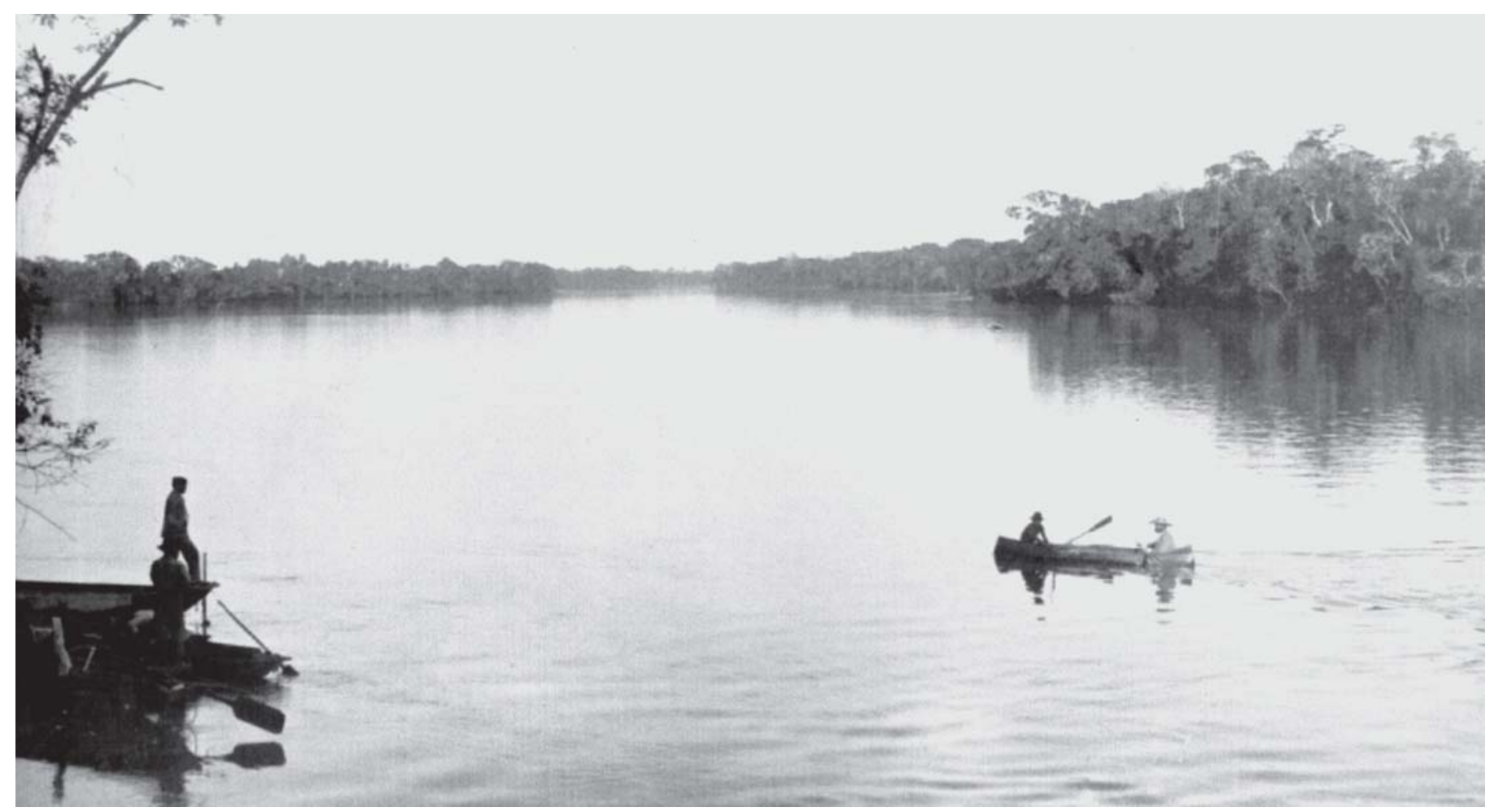

Figura 2 - Porto de Barra Mansa, Rio Tietê (Relatório da expedição do Rio Tietê)

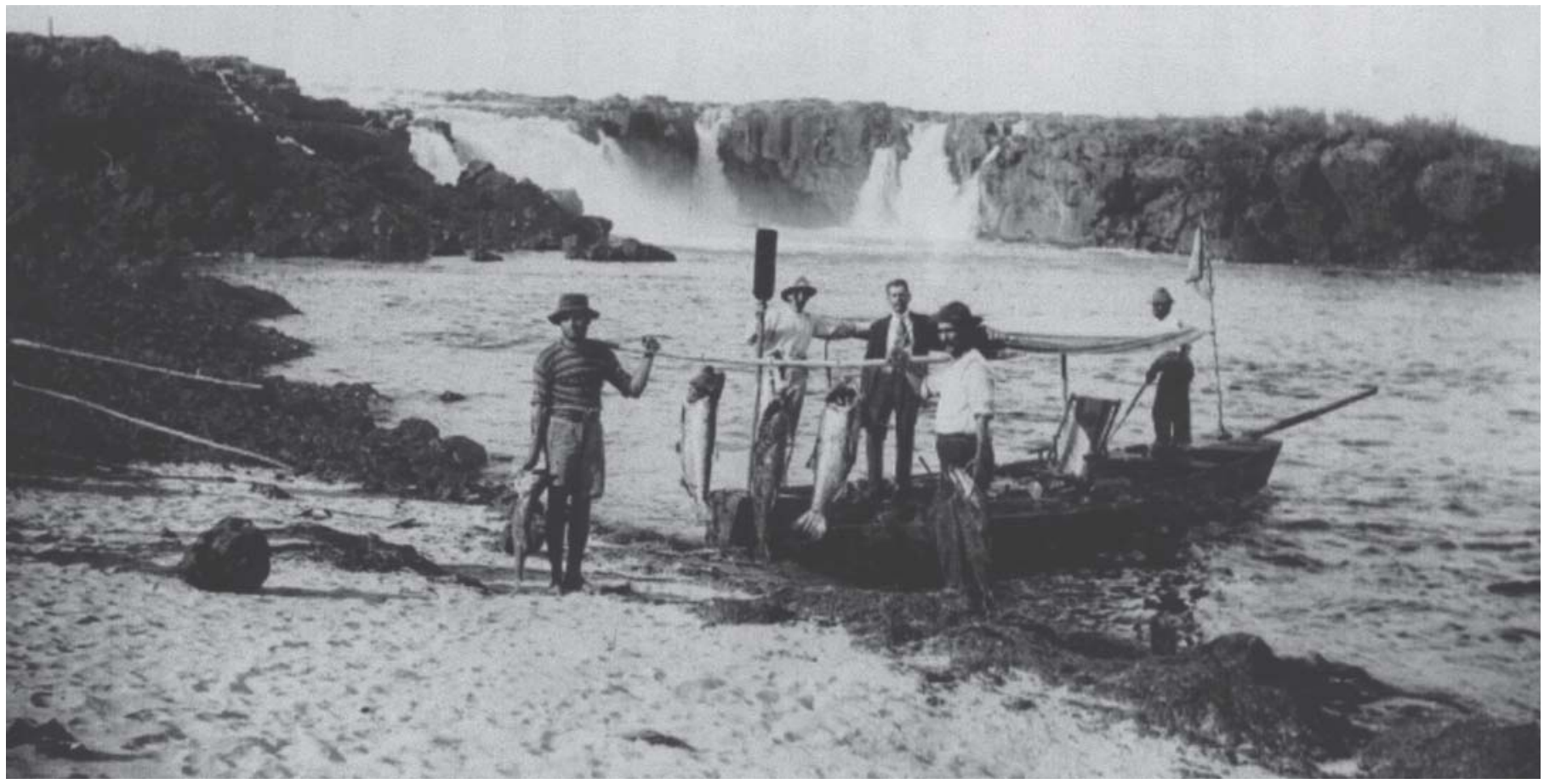

Figura 3 - Regresso da pescaria (trecho do Salto de Urubupungá) (Relatório da expedição do Rio Paraná). O chefe da CGG, João Pedro Cardoso, é o homem de terno e gravata 


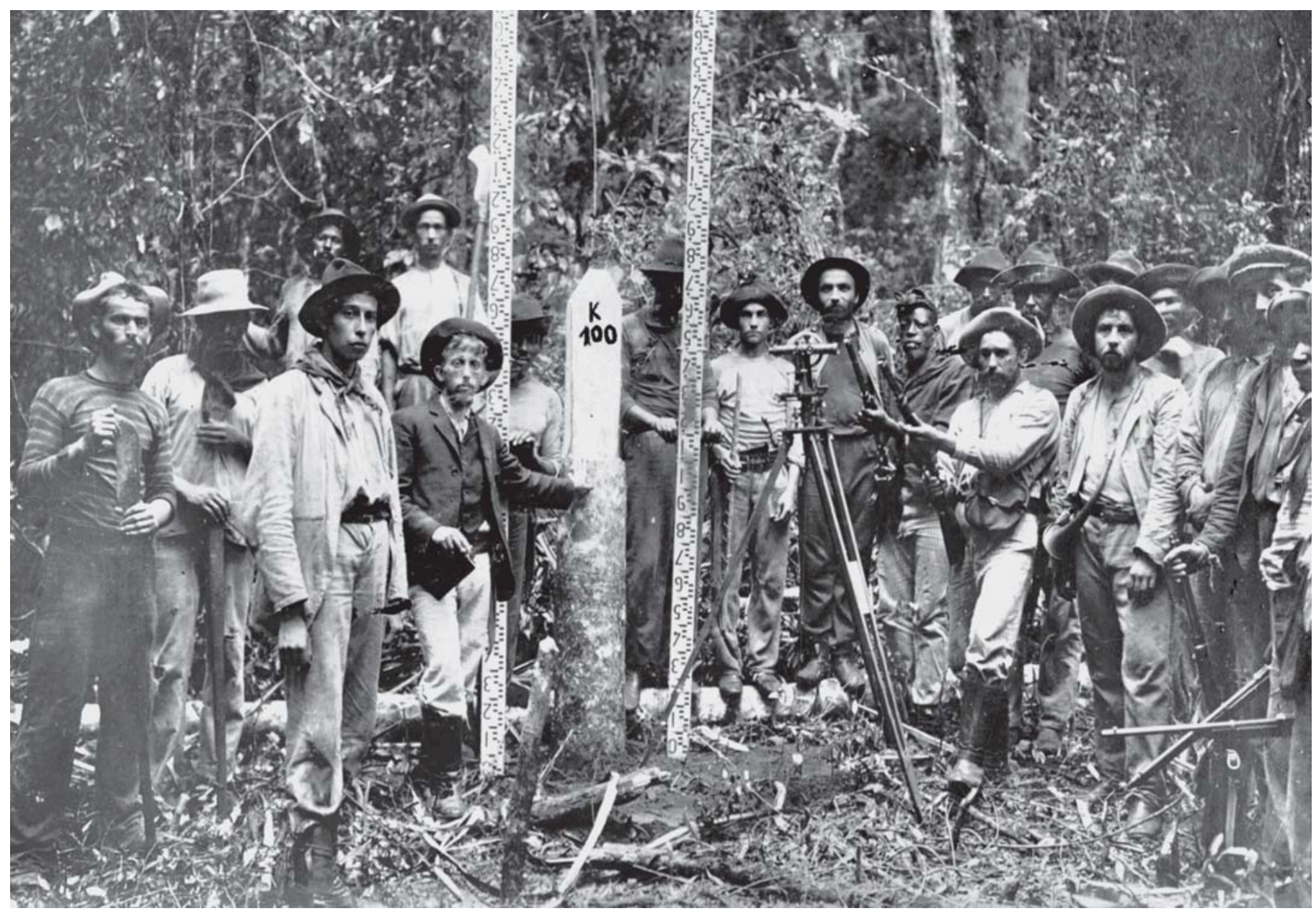

Figura 4 - Picadão no quilômetro 100 (Relatório da expedição do Rio Feio)

\section{Considerações finais}

De fato, passados cem anos das expedições do sertão paulista, podemos avaliar até onde a missão institucional da CGG foi cumprida. Como indicador, pode-se observar o estado de São Paulo hoje e verificar as transformações. Os denominados 'terrenos desconhecidos' foram literalmente engolidos pela 'onda verde' do café a partir de 1920 e viram surgir, no rastro da abertura de largas fazendas, as primeiras vilas e cidades, algumas delas até batizadas em homenagem aos homens públicos que ajudaram a viabilizar a ocupação deste território: Presidente Prudente, Presidente Bernardes, Presidente Venceslau, Presidente Epitácio. Ou seja, quase a metade do território paulista foi ocupada após o início das ações da CGG.

Por sua vez, a comparação entre as fotos panorâmicas de cachoeiras e quedas d'água de São Paulo, que ilustram os relatórios de exploração, e o quadro de produção de energia elétrica no estado revela, quase sem exceção, a transformação desses monumentos naturais 
em usinas hidrelétricas cujos nomes soam familiares: Nova Avanhandava, Bariri, Barra Bonita, Promissão, Marimbondo, Ilha Solteira, Jupiá, Porto Primavera... Ainda que só nas décadas de 1970 e 1980 as construções dessas hidrelétricas fossem concluídas, o trabalho da CGG serviu de base primeira para a montagem desta infra-estrutura energética.

A vida da CGG enquanto tal durou até 1931, quando foi extinta e passou por diversas mudanças institucionais até se transformar no Instituto Geográfico e Geológico, em 1937, mantendo-se com essa configuração até 1976. Mas, como instituição pública, soube se adaptar e continuar a atender demandas governamentais. Com a chegada dos primeiros automóveis, a Comissão confeccionou e publicou seis Cartas dos excursionistas, em escala 1: 200.000, com a cartografia das rodovias então existentes. Idealizadas por Washington Luis, governador para quem, segundo o jargão, "governar era abrir estradas", tais cartas tinham o propósito de auxiliar a autoviação. E a CGG aparecia, assim, reconhecida, no discurso oficial: "publicaram-se cinco secções da Carta dos Excursionistas, com as indicações necessárias à boa marcha nas estradas de rodagem, classificadas em $1^{\text {a }}$ e $2^{\mathrm{a}}$ classe. Por esse trabalho, os que viajarem por estrada de rodagem ficarão bem orientados" (Campos, 1924, p.46-47). Novos tempos, novos caminhos, novas funções, mas uma mesma linha mestra viabilizar o acesso e ampliar as parcelas do território a serem incorporadas e apropriadas.

\section{NOTAS}

${ }^{1}$ João Alfredo Correia de Oliveira era pernambucano de nascimento e bacharel em direito. Praticamente toda a sua carreira foi ligada à administração pública do Segundo Império, em que ocupou cargos de destaque. Foi deputado provincial (1858 a 1861) e deputado geral (1861, 1869 e 1877). Presidiu a província do Pará (1869) e também a Assembléia Legislativa de Pernambuco (1876). Foi ministro do Império e da Agricultura no Gabinete Rio Branco (1871 a 1875) e presidiu São Paulo de outubro de 1885 a abril de 1886. Envolveu-se ativamente na promulgação da Lei do Ventre Livre e da Lei Áurea (em 1888 era ministro da Fazenda e presidente do Conselho de Ministros), além de ter, paralelamente à ação abolicionista, incentivado a imigração européia. Ainda, estabeleceu, no Liceu de Artes e Ofícios, os gabinetes para ensino de ciências naturais e deu-lhes outros melhoramentos. Esteve envolvido na criação da Escola de Minas de Ouro Preto, nas reformas e novas contratações da Escola Politécnica do Rio de Janeiro e na criação da Comissão Geológica do Império. Apresentou proposta para reforma da instrução pública em 1874, fez construir edifícios para novas escolas primárias e reformou algumas das preexistentes. Mandou fazer o primeiro exame científico das águas minerais de Caxambu, Lambari e Poços de Caldas (Egas, 1926, p.615-651).

${ }^{2}$ As poucas e esparsas informações biográficas sobre João Pedro Cardoso não permitem indicar com segurança o ano de seu falecimento.

${ }^{3}$ Sobre as opções de trabalho e os percalços do avanço dos levantamentos em direção ao Oeste de São Paulo, Figueirôa, 1987, 1990.

${ }^{4}$ Ver, por exemplo, Souza Lima, 1989, e Freire, 1990.

${ }^{5}$ Esse aspecto é discutido em Figueirôa, 2006.

${ }^{6}$ Mogiana: região que contém os municípios de Amparo, Batatais, Caconde, Franca, Ituverava, Orlândia, Mogi-Mirim, Mogi-Guaçu, Ribeirão Preto, São José do Rio Pardo, dentre outros. Paulista: região que contém os municípios de Anápolis, Araras, Araraquara, Barretos, Guaíra, Olímpia, Jaboticabal, Leme, Limeira, Rio Claro, Pirassununga, São Carlos, Santa Rita do Passa-Quatro, entre outros. 


\section{REFERÊNCIAS}

BOTELHO, Carlos José de Arruda. Ofício do secretário de Agricultura do estado de São Paulo ao chefe da CGG. São Paulo. Fundo CGG, série Correspondência, subsérie Passiva, caixa 6 (Arquivo Histórico do Instituto Geológico de São Paulo). 13 dez. 1906.

CAMPOS, Carlos.

Mensagem apresentada ao Exmo. Snr. Dr. Carlos de Campos, em 1o de maio de 1924, pelo Exmo. Snr. Dr. Washington Luis P. de Souza, expresidente do Estado de São Paulo. São Paulo: Typographia do Diário Oficial. p.46-47. 1924.

CARRÃO, João da Silva.

Relatório de João da Silva Carrão, presidente da província de São Paulo, apresentado à Assembléia Legislativa Provincial em 3 de fevereiro de 1866. São Paulo: Typographia Imparcial de J.R.A. Marques. p.39, 42. 1866.

CASALECCHI, José Enio.

O Partido Republicano Paulista: política e poder, 1889-1926. São Paulo: Brasiliense. 1987.

DERBY, Orville Adelbert.

Retrospecto histórico dos trabalhos geographicos e geologicos effectuados na província de São Paulo. São Paulo: Leroy King Bookwalter. 1889.

EGAS, Eugênio.

Galeria dos presidentes de São Paulo: publicação oficial do estado de São Paulo comemorativa do 1 o centenário da independência do Brasil. São Paulo: Secção de Obras d'O Estado de S. Paulo. 1926.

FIGUEIRÔA, Silvia Fernanda de Mendonça. Geological surveys in the tropics: the Brazilian experience (1875-1934). Earth Sciences History, New York, v.26, n.1, p.151-171. 2007.

FIGUEIRÔA, Silvia Fernanda de Mendonça. A Repartição Geral dos Telégrafos e o trabalho de Guilherme Schüch de Capanema em geociências. Trabalho apresentado no Simpósio MAST 21 Anos: História das Ciências no Brasil, 10-12 abr. 2006, Rio de Janeiro. 2006.

FIGUEIRÔA, Silvia Fernanda de Mendonça. A formação das ciências geológicas no Brasil: uma história social e institucional. São Paulo: Hucitec. 1997.

FIGUEIRÔA, Silvia Fernanda de Mendonça. Escola Politécnica de São Paulo versus Comissão Geográfica e Geológica: reflexões em torno de uma controvérsia científica. In: LOPES, Maria Margaret; FIGUERÔA, Silvia Fernanda de Mendonça (Org.). O conhecimento geológico na América Latina: questões de história e teoria. Campinas: Instituto de Geociências/Unicamp. p.61-74. 1990.
FIGUEIRÔA, Silvia Fernanda de Mendonça. Um exemplo de aplicação da semiótica à história da ciência através da análise de fotografias de expedições geocientíficas. Quipu, México D.F., v.4, n.3, p.433-445. set-dez. 1987.

FIGUEIRÔA, Silvia Fernanda de Mendonça. Modernos bandeirantes: a Comissão Geográfica e Geológica de São Paulo e a exploração científica do território paulista (1886-1931). Dissertação (Mestrado) - Faculdade de Filosofia, Letras e Ciências Humanas,Universidade de São Paulo. 1987.

FREIRE, Carlos Augusto da Rocha.

Indigenismo e antropologia: o Conselho Nacional de Proteção aos Índios na gestão Rondon (1939-1955). Dissertação (Mestrado) Programa de Pós-graduação em Antropologia Social, Museu Nacional, Rio de Janeiro. 1990.

HOBSBAWM, Eric.

A era do capital (1848-1875). Rio de Janeiro: Paz e Terra. 1979.

MILLIET, Sérgio.

Roteiro do café e outros ensaios: contribuição para o estudo da história econômica e social do Brasil. São Paulo: Hucitec. 1982.

MORAES, Antonio Carlos Robert.

O Sertão: um 'outro' geográfico. Terra Brasilis, Rio de Janeiro, n.4-5, p.11-23. 2003.

MORAES, Antonio Carlos Robert. Território e história no Brasil. São Paulo: Annablume. 2004.

NEWERLA, Vivian Branco.

Rios vistos e revistos: as expedições de exploração do sertão da Comissão Geográfica e Geológica na história da ciência e no ensino de ciências naturais. Dissertação (Mestrado) - Instituto de Geociências, Unicamp, Campinas. 2000.

OLIVEIRA, João Alfredo Corrêa.

Relatório apresentado do presidente da província de São Paulo à Assembléia Legislativa Provincial em 15/02/1886. Revista O IGG, São Paulo, v.18, n.1, p.30. jan-mar 1966.

RESOLUÇÃO...

Resolução 07/04/1886. Revista O IGG, São Paulo, vol.17, n.1, p.30. jan.-mar. 1966.

SANTOS, Francisco Quirino dos. Estrada de ferro. A Gazeta de Campinas, Campinas, p.1. 7 jun. 1874.

SÃO PAULO.

Comissão Geográfica e Geológica. Exploração do rio Tietê: barra do rio Jacaré-Guassú ao rio Paraná. 3.ed. São Paulo: Comissão Geográfica e Geológica. 1930. 
SÃO PAULO.

Comissão Geográfica e Geológica. Relatório apresentado pelo chefe da Comissão Geográfica e Geológica ao secretário de Agricultura do Estado de São Paulo, referente a 1910. São Paulo. jun. 1911.

SÃO PAULO.

Comissão Geográfica e Geológica. Exploração do rio Paraná: I. Barra do rio Tietê ao

rio Parnahyba; II. Barra do rio Tietê ao rio Paranapanema. 2.ed. São Paulo: Comissão Geográfica e Geológica. 1911.
SÃO PAULO.

Comissão Geográfica e Geológica. Exploração dos rios Feio e Aguapehy: extremo sertão do Estado. 2.ed. São Paulo: Comissão Geográfica e Geológica. 1910.

SOUZA LIMA,

Antonio Carlos de. Os museus de história natural e a construção do indigenismo: notas para uma sociologia das relações entre campo intelectual e campo político no Brasil. Mestrado (Dissertação) - Programa de Pós-graduação em Antropologia social, Museu Nacional, Rio de Janeiro. 1989. 